\title{
Corrigendum: Aromatase Derived Estradiol Within the Thalamus Modulates Pain Induced by Varicella Zoster Virus
}

\author{
Phillip R. Kramer ${ }^{1 *}$, Mahesh Rao ${ }^{1}$, Crystal Stinson ${ }^{1}$, Larry L. Bellinger ${ }^{1}$, \\ Paul R. Kinchington ${ }^{2}$ and Michael B. Yee ${ }^{2}$ \\ ${ }^{1}$ Department of Biomedical Science, Texas A\&M University College of Dentistry, Dallas, TX, United States, ${ }^{2}$ Department of \\ Ophthalmology and of Molecular Microbiology and Genetics, Eye and Ear Foundation, School of Medicine, University of \\ Pittsburgh, Pittsburgh, PA, United States
}

Keywords: orofacial, herpes zoster, neuralgia, shingles, pain, estrogen, aromatase, thalamus

\section{A Corrigendum on}

Aromatase Derived Estradiol Within the Thalamus Modulates Pain Induced by Varicella Zoster Virus

by Kramer, PR., Rao, M., Stinson, C., Bellinger, L. L., Kinchington, P. R., and Yee, M. B. (2018). Front. Integr. Neurosci. 12:46. doi: 10.3389/fnint.2018.00046

In the original article, there was a mistake in Figure 3 as published. The value of "mg" should have been " $\mu$ g." The corrected Figure 3 appears below. A correction has also been made to the Material and Methods, Enzyme-linked immunosorbent assay (ELISA).

"Fresh thalamic tissue punches from all five animals in experiment \#3 (Table 1) was stored

OPEN ACCESS

Edited and reviewed by: Vinay V. Parikh, Temple University, United States

\section{*Correspondence: \\ Phillip R. Kramer}

pkramer@tamhsc.edu

Received: 03 December 2018 Accepted: 13 December 2018

Published: 31 January 2019

Citation:

Kramer PR, Rao M, Stinson C,

Bellinger $L L$, Kinchington $P R$ and Yee MB (2019) Corrigendum: Aromatase Derived Estradiol Within the Thalamus Modulates Pain Induced by Varicella Zoster Virus.

Front. Integr. Neurosci. 12:66. doi: 10.3389/fnint.2018.00066 in liquid nitrogen until analysis. Tissue was placed in $250 \mu \mathrm{l}$ of T-Per tissue protein extraction reagent containing Halt Protease Inhibitor and ground (Thermo Scientific, Rockford, IL, USA). Ground samples were frozen and thawed, followed by centrifugation and decanting of the supernatant. Quantitation of VGAT in the supernatant was completed on duplicate $100 \mu \mathrm{l}$ samples of supernatant using an SLC32A1 (VGAT) ELISA following the manufacturer's directions (Cusabio, catalog \#CSB-EL021578MO). Total protein was determined in each sample using a BCA protein assay (Thermo Scientific, Waltham, WA, USA). Values represent the pg of VGAT per $\mu \mathrm{g}$ of total protein."

Additionally, the middle initial was missing in the first author's name. This has been corrected from "Philip Kramer" to "Philip R. Kramer."

The authors apologize for this error and state that this does not change the scientific conclusions of the article in any way. The original article has been updated.

Conflict of Interest Statement: The authors declare that the research was conducted in the absence of any commercial or financial relationships that could be construed as a potential conflict of interest.

Copyright ( 2019 Kramer, Rao, Stinson, Bellinger, Kinchington and Yee. This is an open-access article distributed under the terms of the Creative Commons Attribution License (CC BY). The use, distribution or reproduction in other forums is permitted, provided the original author(s) and the copyright owner(s) are credited and that the original publication in this journal is cited, in accordance with accepted academic practice. No use, distribution or reproduction is permitted which does not comply with these terms. 


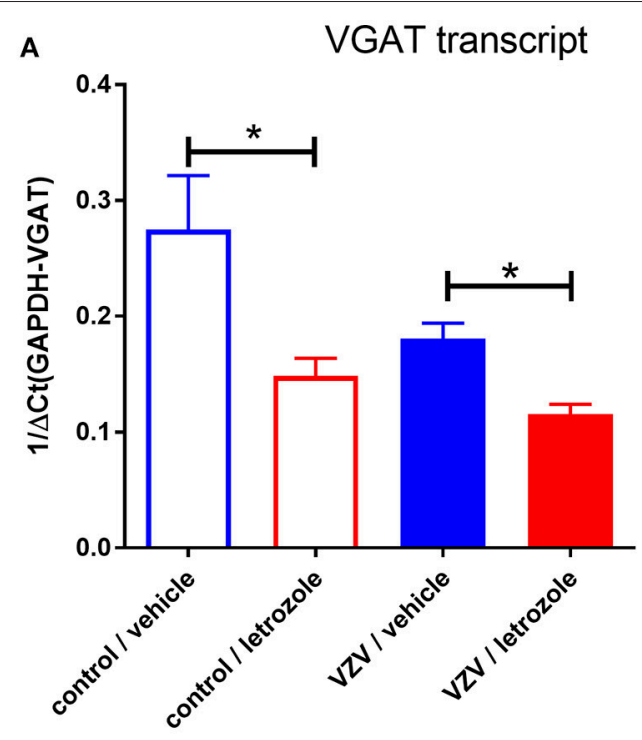

B VGAT protien

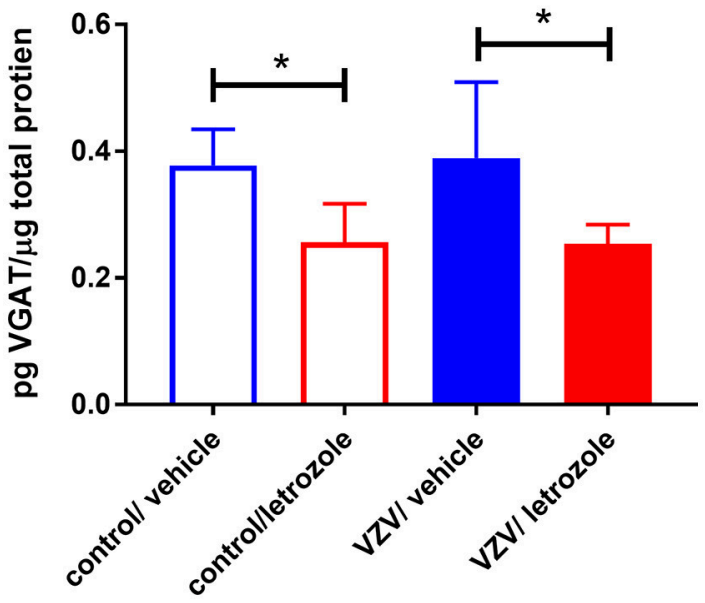

FIGURE 3 | Vesicular GABA transporter (VGAT) expression in the thalamus was significantly reduced after infusing letrozole $5 \mathrm{mg} / \mathrm{ml}$ into the thalamus. Animals were sacrificed after the second week of place escape/avoidance paradigm (PEAP) testing. In panel (A), real time polymerase chain reaction (RT-PCR) was completed after isolating thalamic plugs (four animals per group) and in panel (B) VGAT protein was quantitated after isolating thalamic plugs by enzyme-linked immunosorbent assay (ELISA; five animals per group). The asterisks indicate a significant difference of $p<0.05$. Values are means and SEM. 